\title{
Resolution of Atropisomeric Cyclic Catechol Monoether O-Sulfate Esters by a Molluscan Sulfatase
}

\author{
Makoto N. Masuno ${ }^{\dagger, \|}$ and Tadeusz F. Molinski* ${ }^{*}, \S_{\odot}$ \\ ${ }^{\dagger}$ Department of Chemistry, University of California, 1 Shields Avenue, Davis, California 95616, United States \\ ${ }^{\ddagger}$ Department of Chemistry and Biochemistry and ${ }^{\S}$ Skaggs School of Pharmacy and Pharmaceutical Sciences, University of California, \\ 9500 Gilman Drive 0358, La Jolla, San Diego, California 92093, United States
}

Supporting Information

ABSTRACT: Atropisomeric cyclic catechol ethers are notoriously difficult to resolve by classical chiral phase high-performance liquid chromatography. Here, we show the first application of sulfatase enzymes for the kinetic resolution of $O$-sulfato-catechol ethers with enantioselectivities ranging from 30 to $65 \%$ ee, as determined by preparation of their Marfey's ether derivatives. Substratestructure dependence was briefly explored.

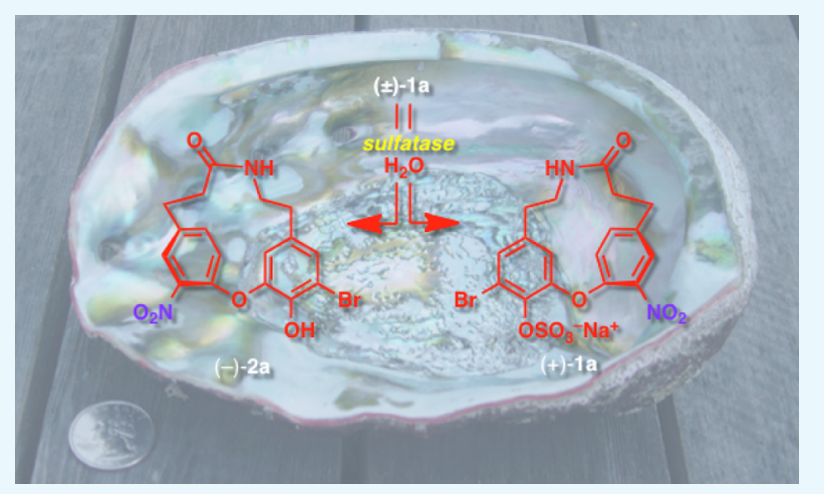

\section{INTRODUCTION}

Enzymes are used extensively in organic synthesis for the kinetic resolution of racemates and desymmetrization of mesocompounds to gain access to enantiomerically enriched starting materials. Most commonly, esterases (lipases) are used for either the hydrolysis of esters or acylation of alcohols, although occasionally other enzyme-substrate pairs have been exploited (e.g., reductase-ketone or aldehyde, oxidase-alcohol, hydrolasenitrile, and so on) to procure enantioenriched precursors. ${ }^{1}$ Sulfatases have found use for biotransformation, ${ }^{2}$ mainly for analytical chemistry, and some examples of enantioconvergent syntheses employing sulfatases with secondary $O$-alkyl sulfate esters have been reported. ${ }^{3}$ To the best of our knowledge, there are no reported examples of kinetic resolution of atropisomeric $\mathrm{O}$-sulfate esters by sulfatases.

Recently, we were tasked with the resolution of a series of racemic, atropisomeric, cyclic catechol monoethers $( \pm)-2$ that are mimics of the natural product bastadin-5, a potent agonist of the RyR1-FKBP12 $\mathrm{Ca}^{2+}$ channel from the marine sponge Ianthella basta. ${ }^{4}$ Macrocycle $\mathrm{pR}-(+)-2 \mathrm{a}$ exhibits planar chirality and, like bastadin-5, stimulates $\mathrm{Ca}^{2+}$ release $\left(\mathrm{EC}_{50} 21 \mu \mathrm{M}\right)$ - the last stage of excitation-contraction in striated muscle-through the RyR1-FKBP12 channel from stores in the sarcoplasmic reticulum. Significantly, the enantiomer (-)-pS-2a is almost 4 times more potent $\left(\mathrm{EC}_{50}=6 \mu \mathrm{M}\right)$ than $(+)-\mathrm{pR}-2 \mathrm{a}^{5 \mathrm{a}}$

Racemic ( \pm )-2a was resistant to separation by chiral phase high-performance liquid chromatography (HPLC) under a variety of conditions ${ }^{a}$ and failed to undergo efficient resolution by acylation in the presence of commercially available lipases. ${ }^{b}$

We found, however, that the corresponding monosulfate esters, $( \pm)-\mathbf{1}$, underwent enantioselective hydrolysis by sulfatases derived from a marine mollusc. Here, we report sulfatasemediated resolution of atropisomeric $O$-sulfato-catechol monomethyl ethers $( \pm)-\mathbf{1} \mathbf{a}, \mathbf{b}$ by the aryl sulfatase from abalone, Haliotis sp., in modest to good enantiomeric excess. The latter result was somewhat surprising as the well-studied aryl sulfatases from other mollusc, Helix pomatia and Patella vulgata, were unreactive under the same conditions. ${ }^{c}$

\section{RESULTS AND DISCUSSION}

A survey of kinetic resolution was carried out with commercially available sulfatases on two substrates: the nitro- and azidosubstituted macrocyclic catechol monoethers $( \pm)-\mathbf{1 a}, \mathbf{b}$ (Scheme $1)$. Both of the latter compounds are masked aniline derivatives that would be suitable precursors for reductive conversion to diazonium salts, $\mathrm{ArN}_{2}{ }^{+}$, and substitution of $\mathrm{N}_{2}$ with a variety of groups (e.g., Sandmeyer reaction: $\mathrm{Cl}, \mathrm{Br}$, or $\mathrm{CN}$ ) to explore modulation of RyR1-FKBP12.

Macrocyclic catechol ethers $( \pm)-\mathbf{2 a}-\mathbf{c}$ were prepared (Scheme 1), starting with atropisomeric $( \pm)$-3, obtained from intramolecular $\mathrm{S}_{\mathrm{N}} \mathrm{Ar}$ cyclization $\left(\mathrm{K}_{2} \mathrm{CO}_{3}\right.$, dimethyl sulfoxide (DMSO)) of the 4-fluoro-3-nitroaryl precursor, as previously described. $^{5 d}$ Initial attempts at sulfation of $( \pm)-2 a$ using conventional reagents (e.g., 1 equiv $\mathrm{Me}_{3} \mathrm{~N} \cdot \mathrm{SO}_{3}$, pyridine $\cdot \mathrm{SO}_{3}$, and sulfamic acid, $\Delta$ ) failed to provide any detectable product $( \pm)-1$ a. Because, in our hands, sulfation of 4-nitrophenol was successful under all of the above conditions, we surmised that the

Received: November 30, 2017

Accepted: January 22, 2018

Published: July 12, 2018 
Scheme 1. Preparation of Atropisomeric Cyclic Catechol Monoether Sulfate Esters

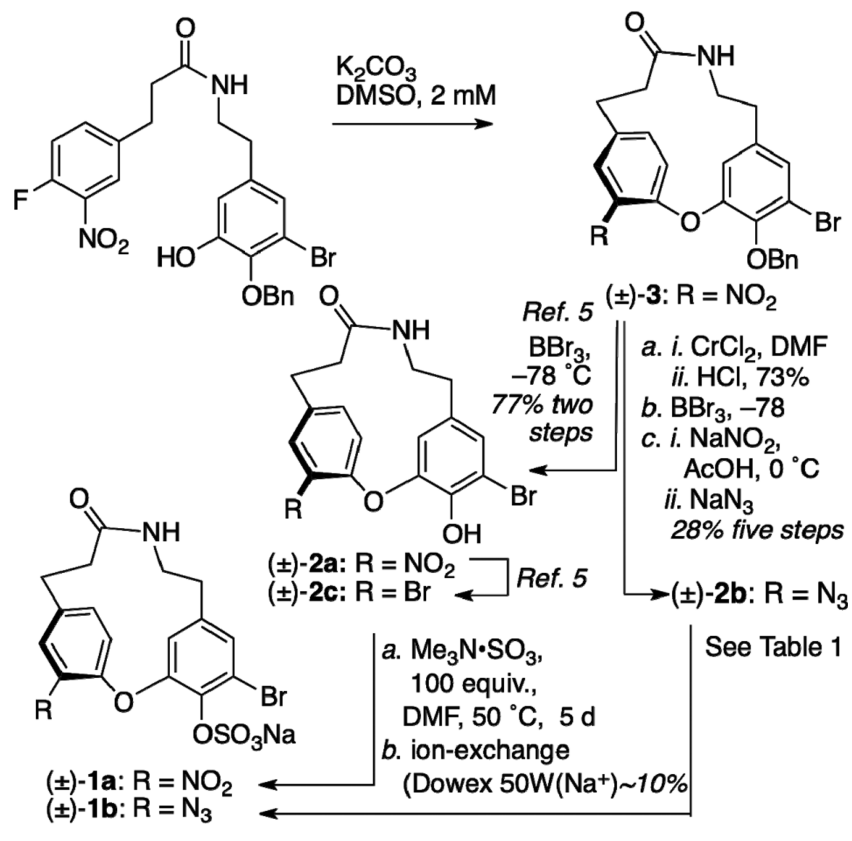

failure of $( \pm)$-2a to react was due to the highly hindered nature of the phenolic $\mathrm{OH}$. Finally, when $( \pm)-\mathbf{2} \mathbf{a}$ or $( \pm)-\mathbf{2 b}$ was treated under forcing conditions ( 100 equiv $\mathrm{Me}_{3} \mathrm{~N} \cdot \mathrm{SO}_{3}$, dimethylformamide, $50^{\circ} \mathrm{C}, 5$ days), acceptable yields $(\sim 10 \%)$ of $( \pm)$-1a,b were obtained for enzyme studies. ${ }^{e}$ The $\mathrm{Me}_{3} \mathrm{NH}^{+}$counterion in each product was exchanged with $\mathrm{Na}^{+}$(Dowex AG $50 \mathrm{~W}-\mathrm{X} 8, \mathrm{Na}^{+}$ form) prior to enzymatic reactions.

The susceptibility of the sulfate esters toward enzymepromoted hydrolysis was examined at two different temperatures (acetate buffer, $\mathrm{pH}$ 6.8) with commercially available sulfatases obtained from three molluscan sources: A, from abalone, Haliotis sp.; B, from the intertidal limpet, P. vulgata; and C, from the Burgundy snail, $H$. pomatia.

In the course of this investigation, an analytical method was required to quantitate the otherwise inseparable enantiomers of $( \pm)-\mathbf{2} \mathbf{a}-\mathbf{c}$. The latter need was met with the development of an HPLC method (Scheme 2), on the basis of conversion of the product catechols, $\mathbf{2 a}-\mathbf{c}$, to the corresponding diastereomeric diaryl ethers $\mathbf{4 a}-\mathbf{c}$ and $\mathbf{5 a}-\mathbf{c}$ with L-Marfey's reagent (1-fluoro2,4-dinitrophenyl-5-L-alaninamide, ${ }^{6} \mathrm{~K}_{2} \mathrm{CO}_{3}$, DMSO, $1 \mathrm{~h}, 23^{\circ} \mathrm{C}$ ) and peak integration.

Scheme 2. Marfey's Derivatives of $( \pm)-2 a-c$. HPLC Analysis

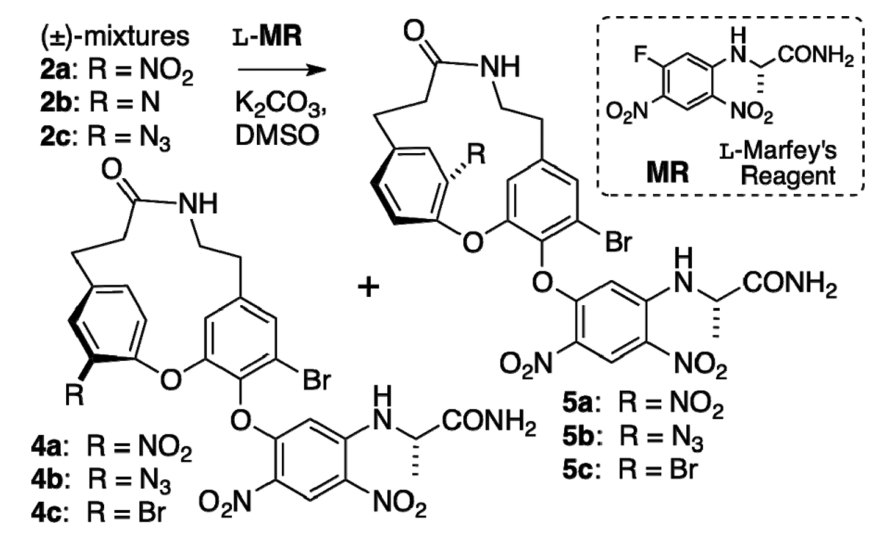

Nitro-substituted macrocycle $( \pm)$-1a underwent reaction (Table 1$)$ with sulfatase $\mathrm{A}\left(22^{\circ} \mathrm{C}\right)$ to give $( \pm)$-2a with modest enantioselectivity $\left(55 \%\right.$ ee, $\left.k_{\text {rel }}=5.2\right)$, which diminished at a higher temperature $\left(37{ }^{\circ} \mathrm{C}, 45 \%\right.$ ee, $\left.k_{\text {rel }}=3.7\right)$. The azidosubstituted macrocycle $( \pm)-\mathbf{1 b}$ was partially resolved in good enantioselectivity at $22{ }^{\circ} \mathrm{C}$ by enzyme A (entry $8,65 \%$ ee, $k_{\text {rel }}=$ $7.9)$ but poorly so at $37{ }^{\circ} \mathrm{C}\left(30 \%\right.$ ee, $\left.k_{\text {rel }}=2.3\right)$. Attempted resolutions of $( \pm)-\mathbf{1 b}$ with enzymes $\mathrm{B}$ and $\mathrm{C}$, at either temperature, were unsuccessful and gave no product.

Assignment of absolute stereostructure of the product (-)-2a (Scheme 3) was achieved through chemical correlation. An independent synthesis of the "syn" atropisomer ( \pm )-6a (X-ray crystal structure ${ }^{5}$ ) followed by enzymatic kinetic resolution (Novozyme 435, vinyl acetate, wet $\mathrm{CH}_{3} \mathrm{CN}, 70^{\circ} \mathrm{C}, 5$ days) gave benzylic $O$-acetate $(-)$-pS-7a, which was easily separated from (+)-pS-2a by flash chromatography (silica). Acetate ester 7a was ammoniolysed $\left(\mathrm{NH}_{3}, \mathrm{MeOH}\right)$ to benzylic alcohol (-)-6a, which was converted (deoxygenation and deprotection, as described elsewhere ${ }^{5}$ ) to (-)-pS-2a (>99\% ee), which was identical, except for optical purity, to that obtained from sulfatase-promoted hydrolysis of $( \pm)-1 a^{f} .^{f}$ Therefore, the enantioselection of Haliotisderived sulfatase A toward ( \pm )-1a is for the $(-)$-pS-enantiomer. ${ }^{g}$

A comparison of the three sulfatases, A, B, and C, showed that only A exhibited hydrolytic activity for kinetic resolutions of $( \pm)-\mathbf{1 a}, \mathbf{b}$. No simple trend was observed in enantioselectivity of the nitro- versus azido-substituted substrates, $( \pm)-\mathbf{1 a}, \mathbf{b}$, and we conclude that the $\pi$-acidity of the aryl ether ring is less important than steric properties of the substituents that impose rigidity on the macrocycle. Unlike sulfatase-promoted hydrolysis of secondary linear alkyl $O$-sulfate esters, the current enzyme active site models are inadequate at explaining either the enantiopreference or factors that determine enantioselectivity in atropisomeric kinetic resolution of $( \pm)$-1a,b.

Wallner and co-workers showed that $O-n$-alkyl sulfate esters of long-chain secondary alcohols undergo hydrolysis in the presence of sulfatase from the archean, Sulfolobus acidocaldarious (Crenarchaea) DSM 639 ( $\mathrm{pH} 2-3$ ), with excellent enantioselectivity (>99\% ee). ${ }^{7}$ Interestingly, for racemic secondary alkyl Osulfates, hydrolysis is enantiospecific and selects for the $R$ enantiomer by $\mathrm{S}_{\mathrm{N}} 2$ reaction with $\mathrm{H}_{2} \mathrm{O}$ at $\mathrm{C}$, with inversion, to give the corresponding $(\mathrm{S})$ secondary alcohol. Consequently, this so-called "inverting" enzyme carries out highly enantioselective kinetic resolutions $(E>200)$ of a limited range of secondary racemic $O$-sulfates to deliver enantioenriched products $(>97 \%$ ee $R) .{ }^{7 h}$ In contrast, sulfatase-mediated hydrolysis of aryl $\mathrm{O}$-sulfates, of necessity, is hydrolyzed by attack of $\mathrm{H}_{2} \mathrm{O}$ at $\mathrm{S}$.

In the present case of kinetic resolution of $( \pm)-1 \rightarrow 2$, the latter mechanism must proceed through a transition state within the enzyme active site that differs considerably from that of $O$ alkyl sulfatases. Molluscan sulfatases (e.g., H. pomatia) are known to be of the aryl sulfatase class and operate through a mechanism that involves transesterification of the aryl sulfate, stabilized within the active site by metal coordination and ligation to Lys and His residues, followed by initial attack on $S$ by one hydroxyl of an aldehyde hydrate i, derived from Ca-formyl glycine (FG, Figure 1), followed by the successive displacement of $\mathrm{ArOH}$ and elimination of bisulfate.

We anticipated that resolution of $( \pm)$-1a would strongly depend on the rigidified chiral space defined by the macrocycle conformation and enzyme active site. We briefly examined the density functional theory (DFT) optimized geometry of $\mathrm{pS}$-1a (B3LYP/6-31+G(d), $\mathrm{H}_{2} \mathrm{O}$ continuum, Figure 2) to ascertain 
Table 1. Sulfatase-Promoted Kinetic Resolution of $( \pm)-1 \mathbf{a}, \mathbf{b}^{a, b}$

$( \pm)-1 \mathbf{a}\left(\mathbf{R}=\mathrm{NO}_{2}\right)$
$( \pm)-\mathbf{1 b}\left(\mathrm{R}=\mathrm{N}_{3}\right)$

${ }^{a}$ Reactions were run with substrate $(10 \mathrm{mM})$ and sulfatase $(15 \mathrm{U})$ dissolved in aqueous buffer $(\mathrm{pH}=6.8,0.25 \mathrm{M}, \mathrm{NaOAc}-\mathrm{HOAc})$ within a conical vial sealed with a Teflon-lined cap. ${ }^{b} k_{\text {rel }}$ was determined at $45 \%$ conversion $(c=0.45)$ measured by UV-HPLC peak integration $\left(\mathrm{C}_{18}\right.$, isocratic $\left.\mathrm{MeOH}-\mathrm{H}_{2} \mathrm{O}-\mathrm{HCOOH}\right)(60: 40: 0.25)$. ${ }^{c}$ Enzymes were used as received (Sigma-Aldrich) derived from the following sources: A, abalone (Haliotis sp.); B, European limpet (P. vulgata); C, Burgundy snail (H. pomatia). ${ }^{d}$ Determined by $\mathrm{HPLC}$ analysis $\mathrm{C}_{18}\left(\mathrm{MeOH}-\mathrm{H}_{2} \mathrm{O}, 60: 40\right)$ or $\mathrm{SiO}_{2}\left(\mathrm{CH}_{2} \mathrm{Cl}_{2}-\right.$ $\mathrm{MeOH}, 97: 3$ ) of Marfey's derivative of 2 (see Scheme 2, L-Marfey's reagent, $\mathrm{K}_{2} \mathrm{CO}_{3}, \mathrm{DMSO}$, room temperature, $1 \mathrm{~h}$ ). See Scheme 3 for determination of absolute configuration of $2 .{ }^{e}$ No product detected. ${ }^{f}$ Calculated using the equation $k_{\mathrm{rel}}=\ln (1-c(1+\mathrm{ee})) / \ln (1-c(1+\mathrm{ee}))$, where ee is the enantiomeric excess of the product and $c$ is the conversion.

\section{Scheme 3. Assignment of Absolute Configuration of Resolved} $(-)-\mathrm{pS}-\mathbf{2 a}$<smiles>O=C(CCc1ccccc1)NCC(O)c1cc(Br)c(OCc2ccccc2)c(OCCCO)c1</smiles>
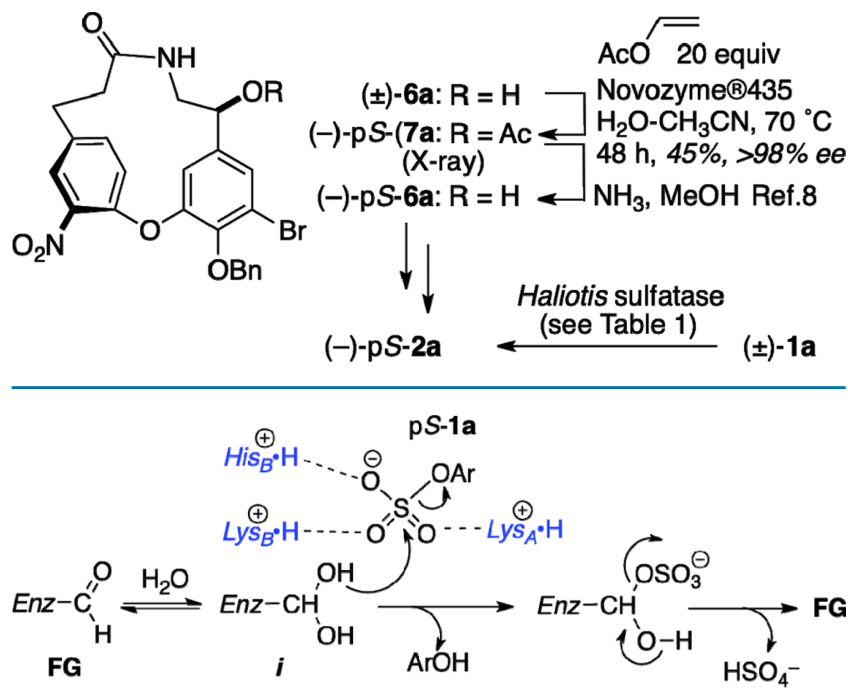

Figure 1. Formyl glycine (FG) active site model for aryl sulfatase enzymes. For clarity, metal ions are not shown. Adapted from ref $2 b$.

intramolecular nonbonded and dipolar interactions that may shed light on the origins of enantioselectivity.

As expected, the two phenyl rings are skewed from each other and subtend a $\mathrm{C}-\mathrm{O}-\mathrm{C}-\mathrm{C}\left(\mathrm{NO}_{2}\right)$ torsional angle of $\theta=-104.4^{\circ}$ to relieve ring strain. No dominant bonding interaction appears between the $\mathrm{NO}_{2}$ group and the $\mathrm{OSO}_{3}{ }^{-}$groups, although this
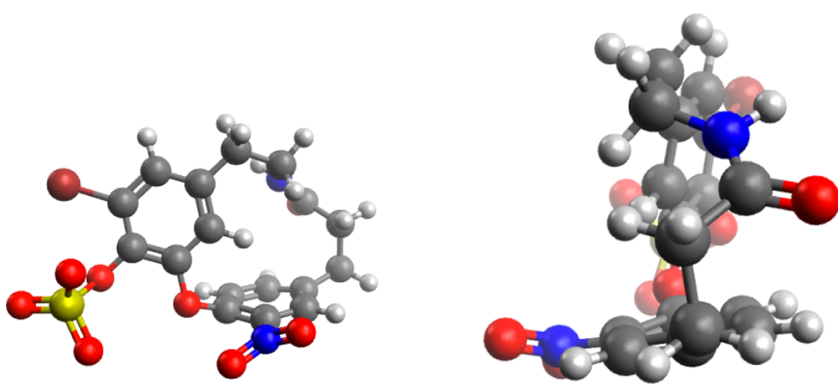

Figure 2. Model of DFT optimized geometry of (-)-pS-1a (geometries at $\mathrm{B} 3 \mathrm{LYP} / 6-31+\mathrm{G}(\mathrm{d})$ level and energies at $\mathrm{B} 3 \mathrm{LYP} / 6-311++\mathrm{G}(2 \mathrm{~d}, \mathrm{p})$ level, $\mathrm{H}_{2} \mathrm{O}$ continuum), (a) and (b) rotated $90^{\circ}$.

will depend on the degree of association with the $\mathrm{Na}^{+}$counterion and solvation. Assuming a similar conformation in the sulfatase binding pocket, the geometry of 1 a appears to favor the approach of a nucleophilic hydrate-enzyme complex (Figure 1) from the catechol face opposite the nitroaryl group, which blocks access to the sulfate group. The product, $(-)-\mathrm{p} S-\mathbf{2 a}$, is favored likely by contacts within the enzyme active site that largely accommodate (-)-pS-1a geometry through nonbonded accommodation of the distal linker atoms and nitroaryl group, rather than a conventional three-point binding model, which stabilizes a particular sulfate-transition state geometry.

Despite the widespread use of molluscan sulfatases in analytical chemistry ${ }^{8}$ and ease of procurement from $H$. pomatia or Haliotis spp., little is known of their enzymology pertaining to kinetic resolution. ${ }^{3}$ 
Specific sulfatases have been isolated from whole tissues of $H$. pomatia, ${ }^{9}$ and the kinetics of hydrolysis of a- and b-naphthol sulfate esters, with an immobilized form of the enzyme, have been studied. ${ }^{10}$ Recently, two sulfastase cDNAs-designated SULF1 and SULF2- have been cloned and characterized from H. pomatia, ${ }^{11}$ opening a window of opportunity for refinement, and directed evolution and improvement of specific activity and enantioselectivity similar to the advantages accorded to sulfatases derived from prokaryotes and archaea (e.g., Sulfolobus). In contrast, similar studies of sulfatases derived from Haliotis have not appeared in the literature.

The preliminary studies described here, together with recent interest in sulfatases, ${ }^{2}$ should provide a foundation for the expanded exploration of sulfatase activity in organic synthesis. Although individual sulfatases have been purified and characterized from the red abalone, Haliotis rufescens, ${ }^{12}$ and other species, no X-ray crystal structures are available yet. ${ }^{13}$ Further studies on organotransformations using sulfatase Haliotis spp. may benefit from cloning and "directed evolution" approaches that have seen great success in refining other classes of enzymes as biocatalysts in organic synthesis (e.g., bacterial lipases, ${ }^{14}$ hydrolases, ${ }^{15}$ oxidases ${ }^{16}$ ).

\section{CONCLUSIONS}

In conclusion, the use of Haliotis-derived sulfatase for kinetic resolution of atropisomeric cyclic monosulfate esters in modest to good enantioselectivity is described for the first time. The study also resulted in a useful analytical HPLC method for determining \% ee in kinetically resolved products-the otherwise inseparable, cyclic atropisomeric catechol monoethers.

\section{ASSOCIATED CONTENT}

\section{S Supporting Information}

The Supporting Information is available free of charge on the ACS Publications website at DOI: 10.1021/acsomega.7b01899.

Preparation, characterization, ${ }^{1} \mathrm{H}$ NMR and ${ }^{13} \mathrm{C}$ NMR of $( \pm)-\mathbf{1 a}$ and $( \pm)-\mathbf{1 b}$, HPLC $t_{\mathrm{R}}$ of Marfey's derivatives, and full details of DFT calculations of (-)-pS-1a (four conformers, $89 \%$ of the Boltzmann population) (PDF)

\section{AUTHOR INFORMATION}

\section{Corresponding Author}

*E-mail: tmolinski@ucsd.edu.

\section{ORCID}

Tadeusz F. Molinski: 0000-0003-1935-2535

\section{Present Address}

"Micromidas, Inc., Sacramento, California 95605, United States (M.N.M.).

\section{Notes}

The authors declare no competing financial interest.

\section{ACKNOWLEDGMENTS}

We thank X. Wang (Merck \& Co., Inc.) for DFT calculations and M. Olmstead for X-ray crystallography. M.N.M. is thankful for support from the Division of Mathematics and Physical Sciences, UC Davis. Funding for this work from NIH (to T.F.M., GM57560) is gratefully acknowledged.

\section{ADDITIONAL NOTES}

${ }^{a}$ Analytical chiral phase columns $(4.6 \mathrm{~mm} \times 250 \mathrm{~mm})$ that were investigated included Chiralpak OD, Chiralpak AD, Pirkle-type (Regis $(R, R)$-Whelk-O1), and Chirex D-penicillamine.

${ }^{b}$ The $O$-acetate ester of $( \pm)-2 a$, in the presence of Novozyme 435 and $n$-butanol (10 equiv, $70{ }^{\circ} \mathrm{C}, 5 \mathrm{~d}$ ), underwent transesterification to give (-)-pS-2a in $50 \%$ ee and only $20 \%$ conversion. Lipases from Candida cylindracea and Pseudomonas sp., under the same conditions, gave (-)-2a in $0 \%$ ee and $5 \%$ ee, respectively.

${ }^{c}$ The aryl sulfatase from $H$. pomatia, although capable of hydrolyzing primary sulfate esters, is unreactive to secondary alkyl sulfates. Schober, M. Ph.D. thesis, 2013, Karl-Franzens University, Graz, Austria.

${ }^{d}$ Control studies and brief investigations of the barrier to rotation in ( \pm -2a suggest that spontaneous racemization of the substrates and products under enzyme incubation conditions is negligible.

${ }^{e}$ Compound $( \pm)-2 \mathrm{c}(\mathrm{R}=\mathrm{Br}$; see ref $5 \mathrm{~b})$ failed to undergo sulfation under any condition.

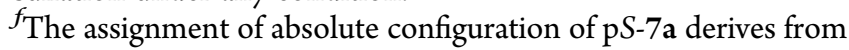
the known enantiopreference of Novozyme 435 for hydrolysis of acetates of benzylic alcohols; however, in the present case, it was also corroborated by independent synthesis of $\mathrm{pS}-7 \mathbf{a}$, starting with the asymmetric Henry reaction of aldehyde ii with $\mathrm{CH}_{3} \mathrm{NO}_{2}$, using Trost's $(R, R)$-catalyst iii to give iv (54\%, $77 \%$ ee). Trost, B. M.; Yeh, V. S. C.; Ito, H.; Bremeyer, N. Effect of Ligand Structure on the Zinc-Catalyzed Henry Reaction. Asymmetric Syntheses of (-)-Denopamine and (-)-Arbutamine. Org. Lett. 2002, 4, 2621-2623. Nitroethanol iv was subsequently converted to (-)-pS-6a. See ref $5 b$.

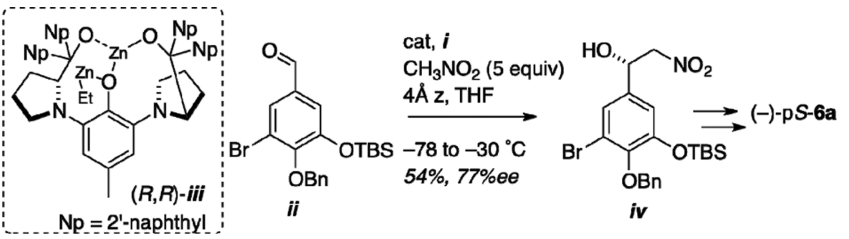

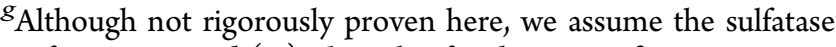
preference toward $( \pm)-\mathbf{2 b}$ is also for the $\mathrm{pS}$ configuration.

${ }^{h}$ It should be noted that the successful kinetic resolutions of Wallner's sulfatase from Sulfolobus acidocaldarius DSM 639 are as much the outcome of extensive screening-selection of sulfurmetabolizing archaea as it is refinement of reaction conditions.

\section{REFERENCES}

(1) Wong, C.-H.; Whitesides, G. M. Enzymes in Synthetic Organic Chemistry; Tetrahedron Organic Chemistry Series; Pergamon: Oxford, 1995; Vol. 12

(2) (a) Toesch, M.; Schober, M.; Faber, K. Microbial alkyl- and arylsulfatases: mechanism, occurrence, screening and stereoselectivities. Appl. Microbiol. Biotechnol. 2014, 98, 1485-1496. (b) Hanson, S. R; Best, M. D.; Wong, C.-H. Sulfotransferases: Structure, Mechanism, Biological Activity, Inhibition, and Synthetic Utility. Angew. Chem., Int. Ed. 2004, 43, 5736-5763.

(3) (a) Schober, M.; Faber, K. Inverting hydrolases and their use in enantioconvergent biotransformations. Trends Biotechnol. 2013, 31, 468-478. (b) Schober, M.; Gadler, P.; Knaus, T.; Kayer, H.; BirnerGrüenberger, R.; Guelly, C.; Macheroux, P.; Wagner, U.; Faber, K. Stereoselective Inverting sec-Alkylsulfatase for the Deracemization of sec-Alcohols. Org. Lett. 2011, 13, 4296-4299.

(4) (a) Kazlauskas, R.; Lidgard, R. O.; Murphy, P. T.; Wells, R. J.; Blount, J. F. Brominated Tyrosine-Derived Metabolites from the 
Sponge Ianthella basta. Aust. J. Chem. 1981, 34, 765-786. (b) Pessah, I. N.; Molinski, T. F.; Buck, E. D.; et al. Bastadins Relate RyanodineSensitive and -Insensitive $\mathrm{Ca}^{2+}$ Efflux Pathways in Skeletal SR and $\mathrm{BC}_{3} \mathrm{H} 1$ cells. Am. J. Physiol.: Cell Physiol. 1997, 272, C601-C614.

(5) (a) Masuno, M. N.; Pessah, I. N.; Olmstead, M. M.; Molinski, T. F. Simplified Cyclic Analogues of Bastadin-5. Structure-Activity Relationships for Modulation of the RyR1/FKBP12 $\mathrm{Ca}^{2+}$ Channel Complex. J. Med. Chem. 2006, 49, 4497-4511. (b) Masuno, M. N. Ph.D. Thesis, University of California: Davis, 2006.

(6) Marfey, P. Determination of D-Amino Acids. II. Use of a Bifunctional Reagent, 1,5-Difluoro-2,4-dinitrobenzene. Carlsberg Res. Commun. 1984, 49, 591-596.

(7) Wallner, S. R.; Nestl, B. M.; Faber, K. Highly Enantioselective secAlkyl Sulfatase Activity of Sulfolobus acidocaldarius DSM 639. Org. Lett. 2004, 6, 5009-5010.

(8) (a) Whalen, J. K.; Warman, P. R. Examination of ester sulfates in Podzolic and Regosolic soils using an immobilized arylsulfatase reactor. Biol. Fertil. Soils 1996, 23, 64-69. (b) Shackleton, C. H.; Roitman, E.; Phillips, A.; Chang, T. Androstanediol and 5-androstenediol profiling for detecting exogenously administered dihydrotestosterone, epitestosterone, and dehydroepiandrosterone: Potential use in gas chromatography isotope ratio mass spectrometry. Steroids 1997, 62, 665-673. (c) Yegles, M.; Mersch, F.; Wennig, R. Detection of benzodiazepines and other psychotropic drugs in human hair by GC/MS. Forensic Sci. Int. 1997, 84, 211-218.

(9) (a) Roy, A. B.; Williams, E. A. The sulphatase of Helix pomatia Purification and kinetic properties. Comp. Biochem. Physiol., Part B: Comp. Biochem. 1989, 93, 229-237. (b) Skorey, K. I.; Johnson, N. A.; Huyer, G.; Gresser, M. J. A Two-Component Affinity Chromatography Purification of Helix pomatia Arylsulfatase by Tyrosine Vanadate. Protein Expression Purif. 1999, 15, 178-187. (c) Roy, A. B. Sulfatases from Helix pomatia. In Methods Enzymology; Academic Press, 1987; Vol. 143, pp 361-366.

(10) Ishikawa, H.; Kurose, K.; Oogaito, M.; Hikita, H. Kinetics and Mechanism of Free and Immobilized Sulfatase from Helix pomatia. J. Chem. Eng. Jpn. 1988, 21, 613-620.

(11) Wittstock, U.; Fischer, M.; Svendsen, I.; Halkier, B. A. Cloning and characterization of two cDNAs encoding sulfatases in the Roman snail Helix pomatia. IUBMB Life 2000, 49, 71-76.

(12) Spaulding, D. C.; Morse, D. E. Purification and characterization of sulfatases from Haliotis rufescens: evidence for changes in synthesis and heterogeneity during development. J. Comp. Physiol., B 1991, 161, 498515.

(13) http://www.rcsb.org.

(14) Liebeton, K.; Zonta, A.; Schimossek, K.; Nardini, M.; Lang, D.; Dijkstra, B. W.; Reetz, M. T.; Jaeger, K.-E. Directed evolution of an enantioselective lipase. Chem. Biol. 2000, 7, 709-718.

(15) Reetz, M. T.; Kahakeaw, D.; Lohmer, R. Addressing the Numbers Problem in Directed Evolution. ChemBioChem 2008, 9, 1797-1804.

(16) Reetz, M. T.; Wu, S. Greatly reduced amino acid alphabets in directed evolution: making the right choice for saturation mutagenesis at homologous enzyme positions. Chem. Commun. 2008, 5499-5501. 